\title{
The role of self-efficacy in predicting treatment adherence in youth with cystic fibrosis
}

Margo M. Szabo

Follow this and additional works at: https://researchrepository.wvu.edu/etd

\section{Recommended Citation}

Szabo, Margo M., "The role of self-efficacy in predicting treatment adherence in youth with cystic fibrosis" (2014). Graduate Theses, Dissertations, and Problem Reports. 7351.

https://researchrepository.wvu.edu/etd/7351

This Thesis is protected by copyright and/or related rights. It has been brought to you by the The Research Repository @ WVU with permission from the rights-holder(s). You are free to use this Thesis in any way that is permitted by the copyright and related rights legislation that applies to your use. For other uses you must obtain permission from the rights-holder(s) directly, unless additional rights are indicated by a Creative Commons license in the record and/ or on the work itself. This Thesis has been accepted for inclusion in WVU Graduate Theses, Dissertations, and Problem Reports collection by an authorized administrator of The Research Repository @ WVU. For more information, please contact researchrepository@mail.wvu.edu. 
The Role of Self-Efficacy in Predicting Treatment Adherence

in Youth with Cystic Fibrosis

by

Margo M. Szabo, B.S.

Thesis submitted to

The Eberly College of Arts and Sciences

at West Virginia University

in partial fulfillment of the requirements

for the degree of

Master of Science
in
Psychology

Approved by

Christina L. Duncan, Ph.D., Committee Chairperson

Elisa Krackow, Ph.D.

Amy Gentzler, Ph.D.

Psychology Department

Morgantown, West Virginia

2014

Keywords: cystic fibrosis, pediatric, treatment adherence

Copyright 2014 Margo M. Szabo 
UMI Number: 1554873

All rights reserved

INFORMATION TO ALL USERS

The quality of this reproduction is dependent upon the quality of the copy submitted.

In the unlikely event that the author did not send a complete manuscript and there are missing pages, these will be noted. Also, if material had to be removed, a note will indicate the deletion.

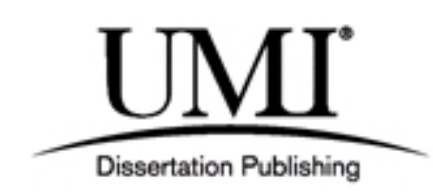

UMI 1554873

Published by ProQuest LLC (2014). Copyright in the Dissertation held by the Author.

Microform Edition () ProQuest LLC.

All rights reserved. This work is protected against unauthorized copying under Title 17, United States Code

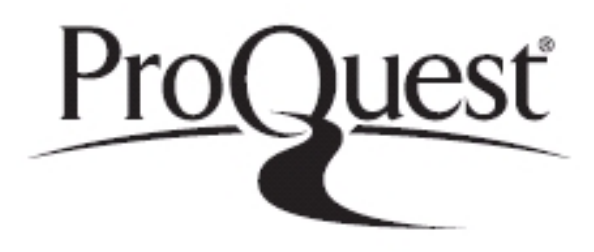

ProQuest LLC.

789 East Eisenhower Parkway

P.O. Box 1346

Ann Arbor, MI 48106 - 1346 


\author{
Abstract \\ The Role of Self-Efficacy in Predicting Treatment Adherence \\ in Youth with Cystic Fibrosis \\ by Margo M. Szabo, B.S.
}

Adolescents with cystic fibrosis (CF) demonstrate relatively poor treatment adherence in comparison to other age groups, which can lead to adverse health outcomes. Though previous research has examined various factors associated with treatment adherence in pediatric CF samples, no studies to date have explored the interrelations among self-efficacy, parental style, level of responsibility for $\mathrm{CF}$ care, and treatment adherence in this population. Therefore, the purpose of this study was to examine the role of self-efficacy, parental style, and level of responsibility for CF care in predicting treatment adherence in adolescents with CF. A sample of 59 adolescents with $\mathrm{CF}$ ( $M$ age $=15.1 ; 56 \%$ male $)$ and their primary caregivers were recruited from three pediatric CF centers across the United States. Results indicated that parental style did not moderate the association between youth self-efficacy and treatment adherence. In addition, neither youth- nor parent-reported division of responsibility for disease management mediated the association between self-efficacy and treatment adherence. However, greater youth self-efficacy was significantly associated with youth taking on more responsibility for their disease management. Findings of the current study suggest promoting self-efficacy during adolescence may increase youth responsibility for their disease management and prepare these youth for the transition from pediatric to adult healthcare. 


\section{ACKNOWLEDGMENTS}

I would like to thank my mentor and committee chairperson, Christina Duncan, for her encouragement and guidance in creating a project that was meaningful and in line with my professional goals. I also would like to thank the members of my committee, Elisa Krackow and Amy Gentzler, for their thoughtful comments that helped refine the details of this project. I am grateful to all the members of the WVU Pediatric Psychology lab for your help with recruitment, data entry, and support throughout this process. I am especially grateful to Lindsay Corman for allowing me to amend her dissertation to create my thesis and spearheading data collection at Boston Children's Hospital. In addition, I would like to acknowledge my collaborators at Boston Children's Hospital and Children's Mercy Hospitals and Clinics, particularly Rebecca Johnson for working tirelessly to coordinate data collection at $\mathrm{CMH}$ despite many obstacles. I am so grateful to all the families who took the time to participate and make this project possible. Finally, I would like to thank my family and my fiancé for their never-ending support throughout this long process and for always believing in my goals. 


\section{TABLE OF CONTENTS}

Abstract....................................................................

Acknowledgements...................................................ii

Table of Contents ...................................................

List of Tables...........................................................

Introduction and Literature Review....................................

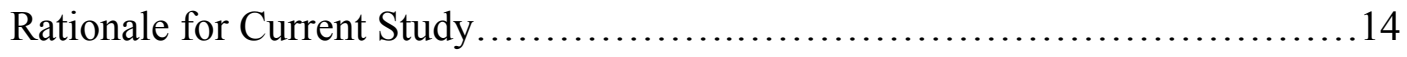

Method............................................................... 19

Participants......................................................... 19

Procedure...................................................... 19

Measures..........................................................21

Results............................................................ 27

Power Analysis.................................................27

Preliminary Analysis.............................................28

Examination of Aims...............................................29

Discussion............................................................ 32

References.......................................................40

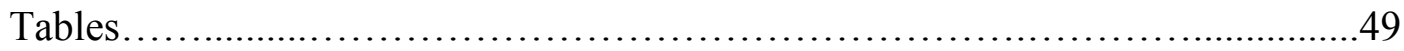




\section{LIST OF TABLES}

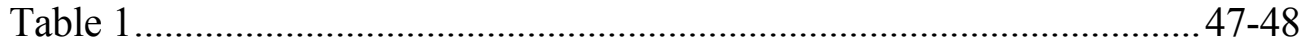

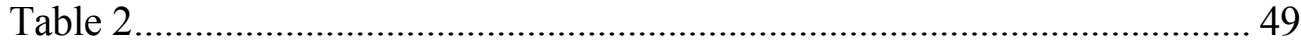

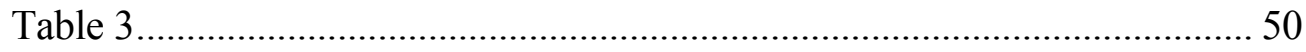

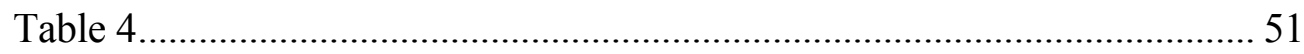




\section{The Role of Self-Efficacy in Predicting Treatment Adherence}

in Youth with Cystic Fibrosis

Cystic fibrosis (CF) is one of the most common life-threatening genetic diseases of the Caucasian population and disrupts the function of several vital body organs, including the lungs and pancreas. More specifically, approximately 30,000 individuals in the United States are currently living with CF (Cystic Fibrosis Foundation, 2011). In addition, CF affects approximately 1 in 3,500 non-Hispanic, Caucasian children, 1 in 4,000-10,000 Hispanic children, and 1 in 15,00020,000 African-American children (Quittner, Barker, Marciel, \& Grimley, 2009). CF is caused by a mutation of the $\mathrm{CF}$ gene, which in turn causes dysfunction of $\mathrm{CF}$ transmembrane conductance regulator (CFTR) protein (Colin \& Wohl, 1994). The dysfunction of the CFTR protein disrupts the flow of water through the chloride channel of cells and leads to the secretion of a sticky mucus that accumulates in many of the body's organs (Colin \& Wohl, 1994).

As mucus accumulates in the body, several vital organs are damaged and individuals with $\mathrm{CF}$ experience disease-related complications. Of these complications, pulmonary infections are the major cause of death (Strausbaugh \& Davis, 2007). In addition to pulmonary infections, gastrointestinal complications and CF-related diabetes are other common manifestations of the disease (Strausbaugh \& Davis, 2007). Therefore, patients with CF must follow a complex treatment regimen to stay healthy, which includes performing daily airway clearance medication and techniques (e.g., bronchodilators, inhaled dornase alpha, nebulized hypertonic saline, and chest physiotherapy), taking inhaled or oral antibiotics, taking pancreatic enzymes with meals and snacks, and eating a daily diet high in calories and fat (Quittner et al., 2009). Due to the complexity of this regimen, patients with $\mathrm{CF}$ often have difficulty adhering to their treatments. Because poor adherence may lead to worst lung functioning and faster disease progression (Abbott \& Gee, 1998; 
Desmond, Schwenk, Thomas, Beaudry, \& Coates, 1983), treatment adherence is a major concern among individuals with $\mathrm{CF}$.

Treatment adherence has been traditionally defined as the extent to which patients comply with a treatment plan that is recommended by a healthcare professional (Rapoff, 1999). However, there is debate surrounding this definition due to individualized treatment plans for patients with the same disease and multiple methods of assessment, which lead to inconsistent rates of adherence (Quittner et al., 2009). For example, using a sample of 37 children with CF (ages 6 to 13), Modi and colleagues (2006) reported widely different adherence rates depending on the assessment method. Rates of adherence for pancreatic enzyme therapy ranged from $27 \%$ using daily phone diary data to $90 \%$ using child self-report data. These authors also found similar patterns of adherence when comparing multiple methods for airway clearance techniques, nebulized medications, and multivitamins. Overall, objective measures of adherence, such as phone diaries, pharmacy refill data, and electronic monitoring, produced significantly lower rates of adherence than parent reports, which suggest self-report measures may be inaccurate and emphasize the importance of examining adherence through multiple methods (Modi et al., 2006).

In addition to different assessment methods, rates of adherence among individuals with $\mathrm{CF}$ differ by age. Czjkowski and Koocher $(1986 ; 1987)$ reported that $35 \%$ of their sample of 40 adolescent and young adult inpatients with CF (ages 13 to 23) were non-compliant when examining physician-reports of adherence, with the oldest patients being the most likely to be noncompliant. Other studies also have demonstrated a higher rate of non-adherence among older children and adolescents with CF, as assessed by self-, parent-, and physician-reports of adherence to medication, chest physiotherapy, and diet (Gudas, Koocher, \& Wypig, 1991; Ricker, Delameter, 
\& Hsu, 1998). These findings suggest that children become less adherent to their treatments as they age. Conversely, a study by Ziadni and colleagues (2006) demonstrated mixed results regarding age-related patterns of adherence to multivitamins (assessed by electronic monitoring) and dornase alpha (assessed through collection of empty medication vials). These authors reported that children younger than 12 years old exhibited a mean adherence rate of $70.5 \%$ for multivitamins, while adolescents older than 12 years old demonstrated a mean lower mean adherence rate of $56.7 \%$ (Ziadni, Streetman, Streetman, \& Nasr, 2006). In this same study, adolescents reported being more adherent to dornase alfa than children younger than 12 years ( $70 \%$ versus $62.9 \%)$. The authors reasoned adolescents might have a higher adherence rate of dornase alfa than younger children because the adolescents experienced more severe lung disease and the effects of this medication on thinning mucus may be perceived as more important for them than for the younger children with milder lung disease.

Although there is evidence that adolescents with CF generally become less adherent to treatment as they age, these age-related patterns do not appear to persist into adulthood as studies have found moderate to high rates of adherence among adults with CF. For example, White and colleagues (2007) stated that $70.2 \%$ of their sample of 57 adults with CF reported good adherence to their daily chest physiotherapy and $91.2 \%$ reported good adherence to their exercise regimen when physically well. Burrows and colleagues (2007) also reported 70\% of their sample of 42 adults exhibited good or moderate adherence to dornase alfa when examining pharmacy refill data. Taken together, this evidence suggests that treatment adherence rates for adolescents are relatively poor in comparison to other age groups of patients with CF. However, these findings should be interpreted with caution, especially in regards to objective adherence data, as the majority of 
studies assessing age-related patterns of non-adherence in patients with CF are based on self- or other-report data.

Due to advances in treatment, patients with $\mathrm{CF}$ are now living into adulthood and require age-appropriate care (Dugueperoux et al., 2008). In fact, the median age of survival of patients with CF was reported to be 38.3 years in 2010, which is an increase from 27 years in 1986 (Cystic Fibrosis Foundation, 2011). Therefore, adolescents must prepare to take responsibility for their disease management (i.e., taking their medications, refilling their medications, calling their physician when ill) and to transition to adult healthcare, which may leave them vulnerable to poor adherence due to less family involvement in their care. Transition has been defined as the process of an adolescent or young adult transferring his or her medical care from a pediatric healthcare setting to an adult healthcare setting (Tuchman, Schwartz, Sawicki, \& Britto, 2010). The median age for transition of an adolescent with CF is approximately 19 years old (McLaughlin, DienerWest, Indurkhya, Rubin, Heckmann, \& Boyle, 2008). However, because transition typically is not discussed before age 17, adolescents have inadequate time to develop necessary skills to manage their CF effectively (McLaughlin et al., 2008).

Additionally, a major area of parental concern regarding their child's transition is the child's ability to independently care for his or her CF (Boyle, Farukhi, \& Nosky, 2001). Pretransition adolescents and post-transition young adults also reported that making their own decisions about their $\mathrm{CF}$ treatment and being responsible for completing their treatments were important skills for a successful transition (Westwood, Henley, \& Willcox, 1999). It is possible that adolescents who lack appropriate skills to care independently for their disease may be at risk for poor treatment adherence and poor health outcomes later in life. Furthermore, a meta-analysis 
of adolescents with various chronic diseases revealed a significant reduction in treatment adherence during the time period surrounding transition (Pai \& Ostendorf, 2011). Moreover, factors related to non-adherence among youth with CF may vary by developmental phase. Therefore, it is important to monitor treatment adherence and explore the factors related to adherence of adolescents with $\mathrm{CF}$ who are preparing for transition.

\section{Factors Related to Treatment Adherence}

Overall, poor rates of treatment adherence among adolescents with CF have generated interest in understanding psychosocial factors that may promote adherence behaviors. As a result, numerous studies have examined the associations among various psychosocial factors and treatment adherence. However, few studies have examined the roles of self-efficacy, parental style, and level of responsibility for $\mathrm{CF}$ care and the interrelations among these variables in predicting treatment adherence of adolescents with CF. Because previous research has explored the association of these variables with treatment adherence using other pediatric chronic illness samples, it is possible that these factors are related to treatment adherence in adolescents with CF. Furthermore, it makes intuitive sense to select these variables as they seem related to the concept of healthcare transition and may be relevant when preparing adolescents with CF to successfully transition to adult-oriented care.

\section{Self-efficacy}

Perceived self-efficacy, an essential component of Bandura's social cognitive theory (1977), is defined as "people's beliefs about their capabilities to produce designated levels of performance that exercise influence over events that affect their lives" (Bandura, 1994). More specifically, Bandura (1977) asserted that individuals who perceive themselves as self-efficacious 
believe they can successfully perform tasks necessary to accomplish their goals. Individuals with high self-efficacy also are more likely to view difficult situations as challenges rather than threats, remain dedicated to accomplishing their goals, and regain their sense of self-efficacy following failed tasks (Bandura, 1977). Children and adolescents who report greater self-efficacy tend to have better psychosocial functioning across a number of developmental domains, including greater academic achievement (Bandura, Barbaranelli, Caprara, \& Pastorelli, 1996), more positive selfimage (Bacchini \& Magliulo, 2003), and better family functioning (Caprara, Pastorelli, Regalia, Scabini, \& Bandura, 2005). When it is examined in chronic illness populations, self-efficacy denotes the patient's confidence in his or her abilities to execute tasks and behaviors necessary to manage his or her disease (Zebracki \& Drotar, 2004). Patients who believe in their abilities to perform disease management tasks may be more likely to engage in these tasks and adhere to their treatment regimens (Holman \& Lorig, 1992). Consequently, it is important to examine the association between self-efficacy and treatment adherence in adolescents with CF.

The association of self-efficacy with treatment adherence and self-management has been examined in several adolescent chronic illness samples, including asthma and insulin-dependent diabetes mellitus (IDDM). For example, Zebracki and Drotar (2004) investigated the relation among patient self-efficacy, treatment adherence, and self-management behaviors in a sample of 77 adolescents with asthma (ages 11 to 17). Their results demonstrated that higher perceived selfefficacy was associated with better self-reported adherence, but not self-management behaviors. Similarly, in a sample of adolescents with IDDM (ages 11 to 18), a positive relation was found between self-reported treatment adherence and self-efficacy (Ott, Greening, Palardy, Holderby, \& DeBell, 2000). Ott and colleagues' results also revealed that older adolescents reported higher 
levels of self-efficacy than younger adolescents, which indicates that youth may need to take responsibility for managing their disease slowly as their self-confidence in their own abilities increases.

In addition to studies with other chronic illness samples, the association between selfefficacy and treatment adherence has been explored in samples of adolescents with CF. Czajkowski and Koocher $(1986 ; 1987)$ administered the Medical Compliance Incomplete Stories Test (M-CIST) to a sample of inpatients with CF aged 13 to 23 and gathered physician reports of compliance to chest physiotherapy, medications and vitamins, diet, and medical tests during the hospitalization. For the M-CIST, participants completed stories focusing on medical compliance issues and these stories were scored based on dimensions of compliance/coping, optimism, and self-efficacy. Czajkowski and Koocher's results yielded a positive association between physicianreported medical compliance and perceived self-efficacy. More specifically, patients who were more compliant with their treatment during hospitalization reported greater self-efficacy. However, the authors explained that patients usually demonstrate better compliance during inpatient hospitalization than when at home, so these findings may not generalize to the larger population of adolescents and young adults with $\mathrm{CF}$.

In a study evaluating the psychometric characteristics of a newly developed measure of self-efficacy, Bartholomew and colleagues' (1993) investigated the relation between self-efficacy and CF self-management skills, such as monitoring for respiratory infections and ensuring adequate nutrition, among a sample of children and adolescents with CF (ages 7 to 18). Parents reported on the self-efficacy of children ages 7 to 12 using a parent version of the questionnaire, while adolescents ages 13 to 18 reported on their own self-efficacy. Their results indicated that 
higher self-efficacy was associated with better self-management skills. In addition, Parcel and colleagues (1994) utilized an instrument to evaluate the self-efficacy of primary caregivers in managing their child's disease with a sample of 199 children and adolescents with CF (ages less than 1 year to 18 years) and their primary caregivers. Their findings revealed that parents who reported higher self-efficacy also reported engaging in more care behaviors on behalf of their child than parents with lower self-efficacy. However, a high correlation between self-efficacy and selfmanagement would be expected for both studies because these variables were assessed via same methods (self- and parent-report).

The results of the aforementioned studies suggest that self-efficacy is an important factor in the study of treatment adherence of adolescents with $\mathrm{CF}$ and may be considered a target of future interventions designed to increase adherence in this population. Nevertheless, much of the current research has relied on subjective measurement of treatment adherence (e.g., self-report), which may inflate the association with self-efficacy due to the shared method variance. In addition, the results of some studies may not generalize to all adolescents with $\mathrm{CF}$ because rates of adherence tend to be higher for inpatients than outpatients and these magnified rates may affect the relation with self-efficacy (e.g., Czajkowski \& Koocher, 1986; 1987). Therefore, future research should include objective measures of treatment adherence and adolescents with CF from outpatient settings to examine the association of self-efficacy and adherence.

\section{Parental Style}

Due to the complexity of the CF treatment regimen, parents often must assist children and adolescents in completing treatment-related tasks, which may in turn place additional stress on the parents and family (Drotar \& Ievers, 1996). Parental style has been conceptualized in terms of two 
primary dimensions, control and warmth, and three different typologies: authoritarian, authoritative, and permissive (Baumrind, 1966). Currently, no studies have assessed parental style in adolescents with CF; however, some research has evaluated the association of other family and parenting factors with treatment adherence in youth with CF. In a study of 200 children and adolescents with Type 1 diabetes, asthma, or CF (ages 8 to 18), Bourdeau and colleagues (2007) found that parents who reported low levels of parenting stress had children and adolescents with higher ratings of self-care behaviors. Another study of youth with CF (ages 9 to 16) demonstrated an association between better treatment adherence and positive family relationships, but no relation between adherence and family problem-solving skills (DeLambo et al., 2004). Additionally, other studies indicated that greater family cohesion and flexibility were related to better self- and parentreported treatment adherence in children and adolescents with CF (Ricker et al., 1998; White, Miller, Smith, \& McMahon, 2009). Overall, findings from previous studies suggest that family and parenting variables are associated with the treatment adherence of adolescents with CF.

Although parental style, per se, has not been examined in CF, the pediatric diabetes literature serves as an excellent example of why parental style is an important factor to consider in the prediction of treatment adherence. Using a sample of 55 children with Type 1 diabetes (ages 4 to 10), Davis and colleagues (2001) demonstrated that children whose parents displayed warmth had better self-reported treatment adherence while parents who displayed a restrictive parental style had children with worse glycemic control (as assessed through glycosylated hemoglobin assays). However, parental restrictiveness was not associated with adherence and parental warmth was not associated with glycemic control. Moreover, Shorer and colleagues (2011) found worse self-reported adherence for adolescents with Type 1 diabetes (ages 11 to 18) whose parents 
reported having a higher sense of helplessness. Their results also demonstrated maternal permissive parenting style was associated with worse adherence, while paternal authoritative parenting style was associated with better adherence.

Additionally, a few studies have investigated the associations among parenting and family factors, treatment adherence, and self-efficacy in children and adolescents with Type 1 diabetes. First, Armstrong, Mackey, and Streisand (2011) reported that children with Type 1 diabetes (ages 9 to 11) who experienced more critical parenting behaviors regarding their treatment regimens displayed lower perceived self-efficacy than those who experienced less critical parenting behaviors. They explained that this finding highlights the detrimental effects of parental criticism on child adjustment, which may put children at risk for poor adherence. Next, a study of 11- to 17year-old adolescents with Type 1 diabetes found adolescents of mothers who demonstrated a style of firm control reported lower levels of self-efficacy (Bulter, Skinner, Gelfand, Berg, \& Wiebe, 2007). In contrast, adolescents of mothers whose parental style was characterized by acceptance reported higher levels of self-efficacy (Bulter, Skinner, Gelfand, Berg, \& Wiebe, 2007). Finally, Berg and colleagues' (2011) study demonstrated that self-efficacy mediated the association between paternal and maternal relationship quality and treatment adherence in a sample of children ages 10 to 14 with Type 1 diabetes. Furthermore, this relation was stronger for older children. Berg and colleagues concluded that early adolescents with high quality parental relationships might develop high levels of self-efficacy, which may prove beneficial as they begin managing their disease autonomously.

Previous research suggests that parenting and family variables are critical factors to consider in the study of treatment adherence of adolescents with CF, particularly as they move 
toward having a more autonomous approach to disease management. Even though parental style has not been examined in youth with $\mathrm{CF}$, studies with other chronic illness groups suggest that parental style is associated consistently with treatment adherence. Furthermore, the literature points to a relation between parenting and family variables and self-efficacy, which may have significant implications in the promotion of treatment adherence of adolescents with chronic medical conditions, including CF.

\section{Level of Responsibility}

As children with CF enter adolescence, they begin to assume greater levels of independence (Quittner et al., 2009). Therefore, it is important to assess the level of responsibility for CF care that is assumed by the adolescent in comparison to the level of responsibility assumed by the parent as this variable and conflicts related to it may result in reduced treatment adherence. Studies with other chronic illness samples, such as asthma and IDDM, have yielded mixed results. Ott and colleagues (2000) found that adolescents with IDDM who reported higher levels of responsibility demonstrated better adherence than those who reported lower levels of responsibility. Self-efficacy also was determined to mediate the relation between level of responsibility and adherence (Ott et al., 2000). Moreover, Walders and colleagues (2000) reported worse adherence for adolescents with asthma (ages 10 to 18) in families that overestimated their child's level of responsibility for taking their medication. In another study of children and adolescents with asthma (ages 8 to 16), no association between level of responsibility and adherence was demonstrated (McQuaid, Kopel, Klein, \& Fritz, 2003).

Several studies investigating the level of responsibility for disease management also have been conducted in samples of children and adolescents with CF. For instance, Williams and 
colleagues (2007) completed qualitative interviews regarding family roles and responsibilities for managing chest physiotherapy (airway clearance) among children and adolescents with CF, aged 7 to 17 , and their parents. They determined that levels of child and parent responsibility for chest physiotherapy varied along a continuum from high parental/low child roles to low parental/high child roles, with lower levels of parental role associated with children's increased autonomy in their disease management. Factors associated with family members' level of responsibility were periods of wellness, periods of illness, and uncertainty regarding the child's efficacy of performing the treatment. Results revealed the following perceived benefits of children assuming more responsibility for their care: a) child-reported benefits: greater flexibility in performing their treatment regimen, decreased feeling of burden on their family, and decreased parental surveillance for the children; b) parent-reported benefits: child's greater level of responsibility and adherence, child's increased autonomy, and less demands on the parents. Although this study provides some insight into the process of transferring disease management responsibilities from parents to children, it suggests a benefit of transferring responsibility is greater treatment adherence but does not directly measure this variable. Therefore, future research should examine whether an association exists between youth level of responsibility and treatment adherence.

Other studies have established age ranges in which children begin to assume responsibility for their CF care. First, Drotar and Ievers (1994) explained that as children with CF and diabetes (ages 4 to 14) aged, their responsibilities for independently managing their illness and treatment increased. More specifically, children aged 11 to 14 with CF performed most of their treatmentrelated tasks either independently or through sharing responsibility with their parents. Their results also indicated that children who exhibited more responsibility for managing their illness also 
exhibited more responsibility in other domains, such as participating in activities away from home. However, parents continued to perform tasks that involved communicating with teachers or physicians, despite the child's age. Second, Modi and colleagues (2008) stated that adolescents begin undertaking more responsibility for their treatment regimen and that parental supervision decreases at age 15. Moreover, results of their study of 103 preadolescents (ages 10 to 13.9) and adolescents (ages 14 to 17) with CF demonstrated that adolescents spend significantly more time completing disease management alone than preadolescents do. However, parents became more involved in disease management again between ages 16-17, which may be due to the adolescents' poor treatment adherence. Taken together, these studies suggest children and adolescents begin taking responsibility for their care between 11 and 15 years of age, but parents continue to maintain some level of responsibility throughout adolescence. Given the variability of parental involvement and youth autonomy across disease-related tasks and ages in adolescence, additional research is necessary to understand the factors that are related to level of responsibility for CF care. In addition, there are mixed results regarding the association of treatment adherence and level of responsibility among children and adolescents with CF. Modi and colleagues (2008) determined that more supervision by mothers of children's disease management activities was significantly associated with better adherence. They explained that adolescents (ages 14 to 17) may need more parental reminders for disease management while preadolescents (ages 10 to 13.9) may need more physical help with these activities. In contrast, Gudas and colleagues (1991) found no relation between level of responsibility and treatment adherence among children and adolescents with CF (ages 5 to 20). Based on these conflicting results, more research should be conducted to clarify the association between level of responsibility for disease management and treatment 
adherence in adolescents with $\mathrm{CF}$, as well as factors that help to explain the relation between these variables.

\section{Summary of Relevant Literature and Rationale for Current Study}

$\mathrm{CF}$ is a genetic disease that disrupts the flow of water through the chloride channel and causes the body to secrete a sticky mucus (Colin \& Wohl, 1994). The accumulation of mucus prevents proper functioning of many vital organs and individuals with CF experience many disease-related complications, such as pulmonary infections and pancreatic insufficiency (Strausbaugh \& Davis, 2007). To maintain optimum health, individuals with CF must adhere to a complex daily treatment regimen, including airway clearance techniques, inhaled or oral antibiotics, pancreatic enzymes, and a high calorie and high fat diet (Quittner et al., 2009). However, patients often exhibit poor treatment adherence, which places them at risk for adverse health outcomes and can unnecessarily shorten their already shortened life span (Abbott \& Gee, 1998; Desmond et al., 1983). Therefore, treatment adherence is a major concern for individuals with CF.

Treatment adherence rates among individuals with CF vary widely based on method of measurement, treatment regimen component, and age group examined. For example, Modi and colleagues (2006) found that children's rates of adherence for pancreatic enzymes ranged from $27 \%$ using daily phone diary data to $90 \%$ using child self-report data. Objective measures of adherence, such as phone diaries and pharmacy refill data, tend to produce significantly lower rates of adherence than self-report measures, which emphasize the importance of examining adherence through multiple methods (Modi et al., 2006). In addition, treatment adherence rates for adolescents, as assessed through objective measures, are relatively poor in comparison to other age 
groups of patients with $\mathrm{CF}$ and range from $57 \%$ to $70 \%$ depending on the component of treatment being measured (Zindani, Streetman, Streetman, \& Nasr, 2006). Variation in adherence also exists because some regimen components able to be measured objectively (e.g., medication and airway clearance) while others are not (e.g., diet). Furthermore, due to advances in treatment, the many patients with CF are now living into adulthood and must transition to adult-oriented healthcare (Dugueperoux et al., 2008). Transition may put older adolescents at additional risk for poor adherence as a recent meta-analysis of adolescents with various chronic diseases revealed a significant reduction in adherence during transition (Pai \& Ostendorf, 2011). This evidence suggests it is important to monitor treatment adherence and explore the factors related to adherence of adolescents with $\mathrm{CF}$, especially those who are preparing for transition.

Ultimately, poor rates of treatment adherence in adolescents with CF have generated interest in psychosocial factors that may promote adherence behaviors. First, adolescents with CF who reported higher self-efficacy also reported better treatment adherence and self-management skills than adolescents with lower self-efficacy (Bartholomew et al., 1993; Czajkowski \& Koocher, 1986; Czajkowski \& Koocher, 1987). Moreover, several studies have demonstrated that lower levels of parenting stress, greater family cohesion and flexibility, and positive family relationships were significantly associated with better treatment adherence in adolescents with CF (e.g., Bourdeau et al., 2007; DeLambo et al., 2004; Ricker et al., 1998; White et al., 2009). However, the relation between parental style and treatment adherence has not yet been examined in $\mathrm{CF}$. Because studies of other pediatric chronic illness groups indicate that parental style is associated with treatment adherence (Davis et al., 2001; Shorer et al., 2011), it is likely that this variable plays an important role in understanding adherence in adolescents with CF. Finally, studies suggest that 
children and adolescents with CF begin taking responsibility for their care between 11 and 15 years of age (Ievers \& Drotar, 1994; Modi et al., 2008). In addition, there are mixed results regarding the association of treatment adherence and level of responsibility for disease management in youth with $\mathrm{CF}$, with some studies suggesting more parental supervision is associated with better adherence (Modi et al., 2008) while other studies suggest no relation (Gudas et al., 1991). These conflicting results point to the need for more research to clarify the association between level of responsibility and treatment adherence in adolescents with CF. However, much of the literature is cross-sectional in nature and therefore, causal relations cannot be inferred. Future research utilizing longitudinal study designs may help to clarify the direction of these associations.

Although studies have examined the associations of self-efficacy, parental style, and level of responsibility for disease management with treatment adherence separately, none have explored the interrelations of these variables in predicting adherence in adolescents with CF. However, studies of children and adolescents with other chronic medical conditions found associations between these variable to be meaningful, suggesting the need to investigate them in CF samples. For example, Berg and colleagues' (2011) study demonstrated that self-efficacy mediated the relation between paternal and maternal relationship quality and treatment adherence in a sample of children with Type 1 diabetes. More specifically, high parental relationship quality (e.g., parent highly communicates love and acceptance of the child) was associated with high adolescent selfefficacy and high self-efficacy was related to better treatment adherence. In addition, the majority of current research on factors associated with treatment adherence has utilized subjective measures of adherence, which may lead to biased results, and suggests the need for future research with objective data. 
Taken together, the results of the aforementioned studies suggest that self-efficacy, parental style, and level of responsibility for CF care may be important factors in the prediction of the treatment adherence of adolescents with $\mathrm{CF}$ and may be considered targets of future interventions designed to increase adherence in this population, particularly as they progress toward transition to adult healthcare. Therefore, the purpose of this study was to examine the role of self-efficacy, parental style, and level of responsibility for CF care, and the interrelations amongst these factors in predicting treatment adherence in adolescents with CF. More specifically, the specific aims and hypotheses of the current study were as follows:

Aim 1: To determine whether parental style (parental care and protectiveness) moderated the relation between youth self-efficacy and treatment adherence. Based on previous research finding of warmth (Davis et al., 2001) and authoritative parenting style (Shorer et al., 2011) being associated with better adherence in pediatric diabetes, the following hypotheses were proposed:

- Hypothesis 1a: Youth who report greater self-efficacy and have caregivers with higher parental care will have better adherence than youth who report greater self-efficacy and have caregivers with lower parental care.

- Hypothesis 1b: Youth who report greater self-efficacy and have caregivers with lower parental protectiveness will have better adherence than youth who report lower selfefficacy and have caregivers with lower of parental protectiveness.

- Hypothesis 1c: Adherence will be the same (i.e., at a high level) when youth report either low or high self-efficacy, but have caregivers with high parental protectiveness. 
Aim 2: To determine whether youth level of responsibility for CF care mediated the relation between youth self-efficacy and youth treatment adherence. Based on Ott and colleagues' (2000) findings that higher levels of youth responsibility were associated with better adherence in adolescents with IDDM, it was hypothesized that greater youth level of responsibility for CF care will mediate the relation between greater youth self-efficacy and better youth treatment adherence. 


\section{Method}

\section{Participants}

The sample included 60 patients with $\mathrm{CF}$ and their primary caregiver. One participant was excluded from all analyses due to lack of prescribed pulmonary medications (see Table 1 for sample demographics). This study included children and adolescents who: a) were between ages 11 and 20 ; b) had a diagnosis of $\mathrm{CF}$ for at least one year prior to recruitment (to have sufficient time to develop adherence to the treatment regimen); and c) had a primary caregiver who was willing to participate with the adolescent. Patients who had a cognitive impairment that prevented them from completing the study questionnaires or who had already transferred their healthcare from pediatric to adult care were excluded from this study. The mean age of patients was 15.12 years $(S D=2.77)$ and $55.9 \%$ of the patients were male. Primary caregivers who participated were primarily mothers $(72.9 \%)$. In terms of lung functioning $\left(\mathrm{FEV}_{1}\right)$, participants were, on average, at low risk for disease severity. However, participants' average health status based on their body mass index (BMI) or BMI percentile was moderate risk.

Participants were recruited from three pediatric CF centers across the United States (West Virginia University’s Mountain State CF Center, Children's Mercy Hospitals and Clinics' CF Center, and Boston Children's Hospital CF Center). The breakdown of participants by recruitment site was as follows: 24 (40.7\%) patients from West Virginia, $19(32.2 \%)$ from Kansas City, and 16 (27.1\%) from Boston. Most patients were recruited during clinic appointments $(\mathrm{n}=53,89.8 \%)$; however, several also were recruited during hospitalization $(\mathrm{n}=6,10.2 \%)$.

\section{Procedure}

Prior to participant recruitment and data collection, the Institutional Review Boards at each CF center approved the study. Potential participants were identified by healthcare staff and asked if 
they were interested in hearing about a research study. After participants agreed to hear about the study, research assistants described the study's purpose and procedures as well as potential risks and benefits of participation in a private clinic or hospital room. Research assistants also discussed confidentiality and HIPPA guidelines with the participants. If participants agreed to the study, the research assistants obtained informed consent from the patient's primary caregiver and patients aged 18-20. Patients aged 11-17 provided assent. In addition, patients or their parents (if patients are ages 11-17) completed the Authorization for Use and Disclosure of Personal Health Information Form so that research assistants could contact the patient's pharmacy and obtain medication refill information.

Each participant then completed a packet of questionnaires with reading assistance provided by the research assistants, if necessary. Caregivers and patients were instructed to fill out their forms independently but could pose questions to the research assistants if some parts of the questionnaires were unclear. The caregivers completed the Family Information Form (was completed with patient, when appropriate) and the Family Responsibility for CF Care-parent version. The patients completed the following questionnaires: a) Chronic Disease Self-efficacy Scales; b) Family Responsibility for CF Care-adolescent version; and c) Parental Bonding Instrument. Either the caregiver or patient completed the Pharmacy Information Form, depending on which family member assumed primary responsibility for refilling the patient's medications. The length of time required to obtain informed consent and complete the questionnaires was approximately 60 minutes. Once the study packets were completed, research assistants briefly checked the forms to make sure that all pages and questions had been filled in correctly and completely. If physicians entered the patient's room during the informed consent process or 
questionnaire completion, research assistants left the room and returned to complete the study procedures after the physician examination was complete.

In addition to the questionnaire packets, the patient's physician or the CF center nurse manager completed the Prescribed Treatment Plan-CF and Medical Information Form while reviewing the patient's medical chart. A research assistant also faxed or mailed a cover letter explaining the study and a copy of the participant's Authorization for Use and Disclosure of Personal Health Information Form to each pharmacy listed on the participant's Pharmacy Information Form to obtain pertinent medication refill data. Phone numbers of participating families were collected on the consent forms in case there were difficulties contacting the pharmacies for medication refill information. Patients received a $\$ 20$ gift card and caregivers received a $\$ 10$ gift card as remuneration for completing the study.

\section{Measures}

Chronic Disease Self-Efficacy Scales (Lorig, Stewart, Ritter, González, Laurent, \& Lynch, 1996). The Chronic Disease Self-efficacy Scales was used to measure adolescents' confidence in managing their CF. This measure yields eight scales with multiple items (exercise regularly; obtain help from family, friends, and community; communicate with physician; manage disease in general; do chores; do social/recreational activities; manage symptoms; manage/control depression) and two one-item scales (get information on disease; manage shortness of breath). Items were rated on a 10-point Likert-type scale regarding confidence in one's abilities from $1=$ not at all confident to $10=$ totally confident. To score each scale, the average of the items for that scale was calculated. Higher scores indicate greater self-efficacy. 
For this study, the following scales were utilized: a) communicate with physician; b) manage disease in general; c) manage symptoms; and d) manage shortness of breath. Internal consistency for the scales used in this study ranged from .87 (manage disease in general scale) to .91 (manage symptoms scale) (Lorig et al., 1996). Test-retest reliability for the aforementioned scales ranged from .82 (manage shortness of breath item) to .89 (manage symptoms scale) (Lorig et al., 1996). The Chronic Disease Self-efficacy Scales have been utilized to assess self-efficacy in samples of adults with heart disease, lung disease, and Type 2 diabetes (Lorig, Ritter, Laurent, \& Plant, 2006; Lorig et al., 2010) and more recently, with a sample of adolescent and young adult survivors of childhood cancer (Taylor, Absolom, Snowden, \& Eiser, 2011). For the current sample, internal consistency of this questionnaire was high $(\alpha=0.95)$.

Family Responsibility for CF Care (Johnson, Adams, Scotten, \& Robinson, 2006). Patient and caregiver levels of responsibility for CF disease management was assessed with the adolescent and parent versions of the Family Responsibility for CF Care questionnaire. Each version of the Family Responsibility for CF Care has 17 items that describe different CF-related treatment tasks, three of which are completed only if the patient has CF-related diabetes. Adolescents and parents rated each item on a 5-point Likert-type scale regarding how responsibility was shared for CFrelated tasks over the past month $(1=$ parent is responsible all of the time, $2=$ parent is responsible most of the time, $3=$ share responsibility equally, $4=$ child is responsible most of the time, 5 = child is responsible all of the time). After rating level of responsibility for each item, adolescents reported whether they would like more responsibility, less responsibility, or no change in responsibility. Similarly, caregivers reported whether they want the adolescent to have more responsibility, less responsibility, or no change in responsibility. Adolescents and caregivers also 
indicated if an item did not apply to the patient's care or if they chose not to do one of the tasks that a physician prescribed.

To score the instrument, the average rating of level of responsibility of the items endorsed is calculated. Lower scores indicate higher parental responsibility for treatment tasks, while higher scores indicate higher adolescent responsibility. In addition, the percentage of items in which the participant believed that the patient's responsibility should increase and the percentage of items in which the participant believed responsibility should decrease can be calculated. For the current study, only the average rating of level of responsibility was utilized in the analyses. Based on pilot data for 23 participants, both parent and youth versions demonstrated high internal consistency for all items, except the diabetes-related items as no participants completed them (parent version: $\alpha=$ 0.94; youth version: $\alpha=0.98$ ) (Johnson et al., 2006). Other psychometric characteristics of the Family Responsibility for CF Care questionnaire are not yet available, as this is a newly developed scale that needs further study. It is noteworthy that there currently are no other questionnaires available to assess the division of responsibility for CF care within families. Internal consistency for the current sample was high for both versions (parent version: $\alpha=0.98$; youth version: $\alpha=$ $0.97)$.

Parental Bonding Instrument (PBI; Parker, Tupling \& Brown, 1979). The PBI is a 25item self-report questionnaire that assesses the patient's perception of his or her primary caregiver's parental style during the first 16 years of his or her life. Items regarding parental behaviors and attitudes were rated on a 4-point Likert-type scale (very like to very unlike). This measure yields two scales: a) care scale (12 items); and b) protectiveness scale (13 items). Nearly half of the items are reverse scored. Low scores on the care scale indicate coldness and neglect, 
while higher scores indicated warmth and empathy. Low scores on the protectiveness scale indicate encouragement of autonomy, while higher scores indicate prevention of autonomy and excessive control. Therefore, high scores on the protectiveness scale suggest a negative rating as patients who have rated caregivers in this way feel as though their caregivers overly restricted their independence during childhood.

In addition, parents can be categorized into one of four different parental styles based on cutoff scores: a) affectionless control (low care and high protectiveness); b) affectionate constraint (high care and high protectiveness); c) neglectful parenting (low care and low protectiveness); and d) optimal parenting (high care and low protectiveness). The $P B I$ has evidenced high internal consistency, as assessed through the split-half method, and high validity based on significant correlations with interview ratings of care and overprotection (Parker et al., 1979). This scale has also been utilized in samples of adolescents with Type 1 diabetes (Graue, Wentzel-Larsen, Hanestad, \& Søvik, 2005) and youth with recurrent abdominal pain (Weydert, Shapiro, Acra, Monheim, Chambers, \& Ball, 2006). For this study, only the care scale and protectiveness scale scores were utilized. Cronbach's alpha coefficient for the current sample were as follows care scale $=0.90$ and protectiveness scale $=0.84$. The parental care scale is hereafter referred to as the parental warmth scale to reduce confusion between this scale and self-management/care behaviors that are part of the $\mathrm{CF}$ treatment regimen.

Family Information Form. The Family Information Form was created for this study to collect data on demographic and medical information about the patient and primary caregiver, such as patient and primary caregiver age, ethnicity, education level, and patient medical history. 
Medical Information Form. The Medical Information Form was created for this study to collect medical data from reviewing the patient's chart, such as number of attended clinic appointments in the past 12 months, number of hospital admissions in the past 12 months, measures of lung functioning (e.g., FEV1), and body mass index (BMI) and its age- and genderbased percentile.

Prescribed Treatment Plan - CF (Modi \& Quittner, 2006; Quittner, Espelage, IeversLandis, \& Drotar, 2000). The patient's physician completed the Prescribed Treatment Plan $-C F$, which collects information on the type, dosage, duration, and frequency of prescribed medications and other components of the patient's treatment.

Pharmacy Information Form. Either the primary caregiver or patient completed the Pharmacy Information Form to provide pharmacy names, addresses, phone numbers, and fax numbers for pharmacies that patients used in the past 18 months to refill prescriptions for all CFrelated medications. However, only medications for pulmonary care that have received an A/B recommendation (i.e., Pulmonary Clinical Practice Guidelines Committee recommends or strongly recommends routinely providing this medication; high certainty of substantial or moderate benefit) in the $\mathrm{CF}$ chronic medications guidelines (i.e., pulmozyme/dornase alpha, inhaled tobramycin, hypertonic saline, colistin, aztreonam lysine/cayston, and Zithromax/azithromycin) were utilized for the current study analyses (Mogayzel et al., 2013). The use of this specific combination of medications to calculate adherence rates has been previously examined in samples of youth with CF (Eakin, Bilderback, Boyle, Mogayzel, \& Riekert, 2011).

Pharmacy refill data were utilized as objective, proxy measures of treatment adherence. Refill information was collected for 18 months to ensure there were sufficient data to capture the 
patient's typical adherence to their treatment regimen. However, only 15 months of data were included in the analyses; the first three months of data collected were excluded from analyses to reduce inaccurate adherence estimates if participants had refilled a medication just prior to the beginning of the reporting period. Participants' adherence to their medication regimens was determining by calculating a Medication Possession Ratio (MPR). The following MPR formula was utilized based on previous research with pediatric CF samples (Eakin et al., 2011):

sum of days supply dispensed between start \& end dates - leftover medication $\times 100$ number of days in the reporting period - number of days in the hospital 


\section{Results}

All statistical analyses were conducted through use of Predictive Analytics Software and Solutions version 21 (SPSS 21).

\section{Power Analysis}

Using the aim with the largest number of predictors (Aim 1), a power analysis using $G$ Power was conducted to approximate the study's sample size. To detect a medium effect size with $80 \%$ power and an alpha of .05 , a sample of 77 participants is needed. To detect a large effect size with the same power and alpha, 36 participants are needed. Using the communication with physician, manage disease in general, and manage symptoms scales of the Chronic Disease Selfefficacy Scales, Taylor and colleagues (2012) found medium and large effect sizes for prediction of adolescent and young adult cancer survivors' self-efficacy by late effects $\left(\beta=-0.22, R^{2}=0.115, p\right.$ $=.004)$ and post-traumatic stress symptoms $\left(\beta=-0.47, R^{2}=0.292, p<.001\right)$. DeLambo and colleagues' (2004) found a medium effect size for the prediction of parent-reported adherence to airway clearance/aerosols of youth with CF by parent-child relationship quality $\left(\beta=0.19, R^{2}=\right.$ $0.149, p<.05)$. Using parental supervision of treatment as predictors of adherence of adolescents with CF, Modi and colleagues (2008) found medium to large effect sizes for adherence to frequency of nebulized treatments $\left(\beta=0.38\right.$, adjusted $\left.R^{2}=0.20, p<.05\right)$ and adherence to duration of nebulized treatments $\left(\beta=0.63\right.$, adjusted $\left.R^{2}=0.31, p<.001\right)$. Although the aforementioned studies utilized different measures of treatment adherence, different measures of predictor variables (e.g., relationship quality versus parental style; parental supervision of treatment versus level of responsibility for disease management), and in one study, a different chronic illness sample, it is assumed that effect sizes in this study will be comparable. Therefore, this study aimed to recruit approximately 60 participants to detect a medium to large effect size. 


\section{Preliminary Analyses}

First, all data were reviewed to locate any missing data and to ensure that all missing data were random. Review of data revealed minimal amounts of missingness across study variables. Two participants were missing data from the entire Family Responsibility for CF Care - youth report and one participant was missing data from the entire Family Responsibility for CF Careparent report. These participants were excluded for relevant analyses in aim 2 . Person-mean imputation (i.e., substituting the participant's mean score of completed items on a scale for the items that were not completed) was utilized to address missingness for other participants (all who had less than $10 \%$ missing data).

Next, study variables were examined for skewness, kurtosis, and univariate outliers. These analyses revealed no outliers and two negatively skewed and kurtoic variables (Chronic Disease Self-efficacy Scales and Parental Bonding Instrument - warmth scale). To attempt to correct these issues, squareroot, log, and inverse transformations were performed. However, none of these transformations corrected the skewness or kurtosis of self-efficacy and parental warmth and therefore, the variables were retained in its original form. Descriptive statistics for all primary study variables are presented in Table 2 .

Examination of study variables by site revealed no significant differences, except with the Parental Bonding Instrument. Youth recruited from the Boston center $(M=6.25, S D=4.54)$ reported significantly lower levels of parental protection than youth recruited from the West Virginia $(M=12.99, S D=6.69)$ or Kansas City centers $(M=14.48, S D=7.99)$. Additionally, youth recruited from the Kansas City center $(M=25.13, S D=9.94)$ reported significantly lower 
levels of parental warmth than youth recruited from the West Virginia $(M=30.67, S D=4.32)$ or Boston centers $(M=31.35, S D=3.60)$.

Finally, Pearson and Spearman correlations were conducted with demographic and medical variables (e.g., patient age, number of clinic appointments attended), and the dependent variable (i.e., treatment adherence) to determine if any potential covariates need to be controlled for in the primary analyses. These correlations revealed a significant association between mother's level of education and adherence, such that lower levels of maternal education were related to better adherence $(r=-0.32, p=0.01)$. Due to its significant association with treatment adherence, maternal level of education was controlled for in the first step of all subsequent analyses. However, because two participants were missing data for maternal level of education, they were excluded from all subsequent analyses.

\footnotetext{
Aim 1

The first aim was to determine if there is a moderation effect for treatment adherence. First, the predictor (youth self-efficacy) and the moderator (parental warmth or protectiveness) were centered as both variables utilize a continuous scale. Next, the centered predictor and centered moderator were multiplied to create a product term to denote the interaction between the two variables. Three hierarchical multiple regressions were conducted with treatment adherence as the dependent variable. For each regression, the centered predictor (youth self-efficacy) and moderator (parental warmth or protectiveness) variables were entered in Block 1 and the product term (interaction between youth self-efficacy and parental warmth or protectiveness) was entered in Block 2.
} 
Results of the first hierarchical regression revealed no significant moderation effect for the PBI - warmth scale on the association between self-efficacy and treatment adherence (see Table 3). Similarly, the PBI-protectiiveness scale did not demonstrate a moderator effect on the association between self-efficacy and treatment adherence (see Table 4). For both moderation analyses, the only significant association was between maternal level of education and treatment adherence $(\beta=-0.26, p=0.05)$.

\begin{abstract}
$\operatorname{Aim} 2$
The second aim was to determine if there is a mediation effect for treatment adherence. Using Baron and Kenny’s approach (1986) for testing mediation, three simultaneous, multiple regressions were calculated for treatment adherence. The first regression examined the relation between the predictor (youth self-efficacy) and the hypothesized mediator (youth level of responsibility for $\mathrm{CF}$ care). The second regression examined the relation between the predictor (youth self-efficacy) and the dependent variable (treatment adherence). The third regression examined the relation among the predictor (youth self-efficacy) and hypothesized mediator (youth level of responsibility for CF care), and the dependent variable (treatment adherence).

Due to missingness, the first mediation model had a sample size of 55 (Family Responsibility for CF Care - youth report). Step 1 of model revealed no significant association between self-efficacy and treatment adherence $(\beta=-0.05, p=0.74)$. Step 2 demonstrated a significant association between self-efficacy and youth-reported level of responsibility, such that youth who reported being more self-efficacious also reported taking on more responsibility for their disease management $(\beta=0.42, p=0.002)$. In Step 3 of the model, youth-reported level of
\end{abstract}


responsibility did not significantly mediate the association between self-efficacy and treatment adherence $(\beta=0.16, p=0.29)$.

Due to missingness, the second mediation model had a sample size of 56 (Family Responsibility for CF Care - parent report). Similar to the first mediation model, no significant association between self-efficacy and treatment adherence was found for the second mediation model $(\beta=-0.04, p=0.77)$. Step 2 revealed a significant association between self-efficacy and parent-reported level of responsibility, such that youth who reported being more self-efficacious were reported by their parents to take on more responsibility for their disease management $(\beta=$ $0.31, p=0.02)$. Lastly, parent-reported level of responsibility did not have a significant mediator effect on the association between self-efficacy and treatment adherence. $(\beta=-0.10, p=0.48)$. 


\section{Discussion}

The aims of the current study were twofold: 1) determine whether parental warmth and protectiveness moderated the relation between youth self-efficacy and treatment adherence; and 2) determine whether youth level of responsibility for CF care mediates the relation between youth self-efficacy and youth treatment adherence. Contrary to hypotheses, neither parental warmth nor protectiveness moderated the association between youth self-efficacy and treatment adherence. In addition, neither youth- nor parent-reported division of responsibility for disease management mediated the association between self-efficacy and treatment adherence. In fact, self-efficacy was not significantly associated with treatment adherence. However, greater youth self-efficacy was significantly associated with youth taking on more responsibility for their disease management. Overall, the study results did not support the proposed hypotheses.

While previous research has demonstrated a significant relation between self-efficacy and treatment adherence in youth with CF (Bartholomew et al., 1993; Czajkowski \& Koocher, 1986; Czajkowski \& Koocher, 1987), this study's findings did not support this association. One possible explanation for this may be method of assessing adherence. Prior research has primarily utilized subjective measures of treatment adherence, such as self-report questionnaires (Bartholomew et al., 1993; Czajkowski \& Koocher, 1986; Czajkowski \& Koocher, 1987), while this study utilized a more objective measure of adherence (i.e., pharmacy refill data). It is possible that previous studies demonstrated an association between self-efficacy and adherence due to shared method variance, which was not present in the current study.

Another possible explanation for the conflicting results is that the current study's sample primarily included outpatients rather than inpatients, with the latter primarily comprising the samples of previous studies (Czajkowski \& Koocher, 1986; 1987). Because adherence rates among 
inpatients tend to be higher than among outpatients, it may be that self-efficacy is only an important factor in patients who demonstrate high rates of adherence. For those with low rates of adherence, confidence in one's abilities to manage their disease may have less association with adherence than other barriers, such as time management and forgetfulness (Modi \& Quittner, 2006). It is possible that relative to self-efficacy, the aforementioned barriers impacted the current sample's adherence rates more significantly. Indeed, mean adherence for this study's participants was $20.2 \%$, which is considerably lower than rates (median Composite MPR $=63 \%$ ) reported in a previous study using pharmacy refill data (Eakin et al., 2011). However, Eakin and colleagues' study utilized a much larger age range (age 6 to 35+) than the current study (ages 11 to 20). This study focused on adolescence, when adherence is notoriously the poorest among patients with CF, and therefore, it is logical that adherence is much lower in the current study. This study's mean adherence also was much lower than previous studies focusing on outpatient adolescents with $\mathrm{CF}$ (Ziadini et al., 2006). However, Ziadini and colleagues utilized electronic monitoring to assess adherence so differences in measurement technique may account for differences in mean adherence rates.

Lastly, previous studies have utilized CF-specific self-efficacy measures while the current study utilized a general disease self-efficacy measure that had not been validated with CF samples. The general disease self-efficacy measure may have failed to capture important aspects of selfefficacy for individuals with CF, which may be more relevant to their adherence. However, the general disease self-efficacy measure was chosen for the current study due to a lack of psychometric data on the only available CF-specific measure and being unable to obtain the measure from the authors (Bartholomew et al., 1993). 
The lack of relation between parental style and treatment adherence was surprising given previous literature with other pediatric chronic illnesses (Davis et al., 2001; Shorer et al., 2011). However, given that earlier research in CF has found associations only between adherence and other family/parenting variables (Bourdeau et al., 2007; DeLambo et al., 2004; Ricker et al., 1998), it may be that parental style is not as important a factor for youth with $\mathrm{CF}$ as other family/parent variables (e.g., family cohesion). For example, Bourdeau and colleagues examined the relation between parental overprotection and adherence in a sample of youth with type 1 diabetes, asthma, and CF, but found no significant associations among these variables in any disease group. It is possible that the family/parenting variables that have previously demonstrated associations with treatment adherence are more pertinent than parental style in how well a patient follows their treatment regimen. For example, parent-child interactions surrounding disease management tasks may not only be more relevant to treatment adherence, but also may be more objectively assessed through behavioral observations and demonstrate a clearer relation with adherence. Finally, the $P B I$ may not be the best measure of parental style as it asks youth to recall their parents' behavior over the first 16 years of the patient's life and the patients may be inaccurately rating their parents' style due to recall biases. Utilizing a measure of parental style with a shorter recall time frame may lead to different results regarding the association of parental style and adherence.

Level of responsibility for disease management also did not demonstrate a significant association with treatment adherence. Previous literature examining this association has been mixed with some studies suggesting an association exists (Modi et al., 2008) and some studies suggesting no association (Gudas et al., 1991). The addition of this study's results to the current literature adds to the ambiguity of the relation between level of responsibility and treatment 
adherence among youth with CF. Similar to studies examining self-efficacy, many studies that demonstrated significant associations between level of responsibility and treatment adherence among other pediatric illness groups utilized subjective adherence measures (Ott et al., 2000; Walders et al., 2000). Therefore, it is possible these previously demonstrated associations might be accounted for by shared method variance.

Although this study's hypotheses were not supported by the results, one interesting finding emerged: youth who reported higher levels of self-efficacy also reported taking on greater responsibility for their disease management. This finding is consistent with Ott and colleagues' (2000) finding that self-efficacy was significantly related to level of responsibility in youth with IDDM. It may be that youth's confidence in their abilities to manage their disease is associated with them independently performing self-management tasks (e.g., taking medication, calling their physician when ill), but that this autonomy does not translate into regimen adherence. On the other hand, it is possible that youth who take on more responsibility for their disease management develop greater self-efficacy due to that increased responsibility. Nevertheless, it may be important to promote self-efficacy during adolescence in order to increase youth independence in their disease management and prepare them for the transition from pediatric to adult healthcare. Making decisions about disease management and being responsible for completing treatments are important skills for successful transition (Westwood et al., 1999). Moreover, it is possible that adolescents who lack appropriate skills to care independently for their disease may be at risk for poor health outcomes later in life. Therefore, it is essential that youth begin taking on responsibility for disease management tasks during adolescence when they have parental supervision to ensure they are accurately performing these tasks. Given the established association between self-efficacy 
and youth responsibility, interventions aimed at increasing youth confidence in their disease management abilities may in turn increase their level of responsibility. Such interventions may include parental modeling of tasks for the adolescent, scaffolding with the adolescent to increase their accuracy in task performance, and praising the adolescents for independently and accurately completing disease management tasks.

In addition, an unexpected relation between maternal level of education and treatment adherence was demonstrated, such that lower levels of maternal education were associated with better adherence. This finding is inconsistent with previous literature in CF that has either demonstrated a positive association between maternal education and adherence (Gudas et al., 1991) or no significant association between these variables (Bourdeau et al., 2007; Delambo et al., 2004; Modi et al., 2008; Ricker et al., 1998; White et al., 2007). Given that the majority of previous research revealed no significant association between maternal education and adherence, it is possible the negative correlation found in the current study is due to type I error. On the other hand, there may be other variables, such as trust and beliefs about decision-making ability, which underlie the relation between high level of education and low adherence. For example, literature reviews on treatment adherence to medications in adults with heart-related issues (e.g., hypertension, high cholesterol) revealed findings similar to the current study (Jin, Sklar, Oh, \& Li, 2008; Kneeland \& Fang, 2010). These authors explained that individuals with higher levels of education may be more likely to be non-adherent due to inflated self-confidence in decision making capabilities and distrust of medical providers. Thus, some of these same variables may play a role in the adherence of youth with $\mathrm{CF}$ who have highly educated mothers. However, additional research should be conducted to clarify the association of maternal education and 
treatment adherence in pediatric CF and to determine whether the aforementioned factors mediate this relation.

Despite the current study's strengths, there are a few limitations worth noting. First, all data collected are cross-sectional in nature and thus, causality of associations cannot be inferred. Future research that utilizes longitudinal methods is warranted to determine the direction of associations among variables. Additionally, all the measures utilized in this study focused on different time frames (e.g., PBI assessed parental style across 16 years of the patient's life whereas the Chronic Disease Self-Efficacy Scales assessed patient self-efficacy at the present time). Therefore, it is possible the lack of significant associations between study variables may be a function of the different time frames of the measures. For example, it may that parental style at the present time is associated with the youth's current rate of treatment adherence, but this association was not captured by the current study given the different time frames. It also is possible the association between youth self-efficacy and family division of responsibility was evidenced due to measurement time frames as these measures both assessed the constructs at the present/current time.

Moreover, though pharmacy refill data were chosen to index treatment adherence because they are more objective than questionnaire data, these data are not without their own limitations. Pharmacy refill data only provide an estimate of medication possession, not an assessment of medication ingestion; thus, it is possible that patients may be refilling their medications but not actually taking them (Choo et al., 1999; Eakin et al., 2011). In addition, pharmacy refill data may over-estimate adherence because families may stockpile medications (Choo et al., 1999; Eakin et al., 2011) or parents may utilize one prescription for multiple children who have CF. However, the 
aforementioned limitations suggest adherence ratings would be higher instead of lower than expected. In contrast, families not providing a comprehensive list of the pharmacies they use to fill the patient's medications on the Pharmacy Information Form may explain this study's low adherence rates. It is possible families simply listed the pharmacies they currently use rather than listing all pharmacies they have used during the pharmacy refill data collection time frame (i.e., the past 18 months). In addition, patient treatment plans and medications frequently change based on the patient's health status; however, this study only used the patient's most recent treatment plan to compare to the pharmacy refill data and thus, did not account for such changes in prescribed medications. Therefore, future research utilizing other objective measures of adherence (e.g., electronic monitoring) may reveal associations between variables not demonstrated in this study.

Overall, the results of this study did not support the proposed hypotheses. No significant moderation effect for parental style or mediation effect for level of responsibility was found for self-efficacy and treatment adherence. Nevertheless, the current study had a number of methodological strengths. This was a multi-site study with a relatively large sample size compared to previous studies on treatment adherence in CF samples ( $N$ 's $=33-40$; Czjkowski and Koocher, 1986; 1987; Eakin et al., 2011; Ziadini et al., 2006). In addition, this study utilized a multi-method, multi-informant approach to assess study variables and therefore, was not subject to the limitation of results due to shared method variance. Treatment adherence is a complex behavior that includes many disease regimen tasks that were not assessed by the pulmonary composite MPR of the current study. For example, chest physiotherapy (e.g., vest, acapella) is an important component of the CF treatment adherence; however, this component is not a medication and therefore, adherence to it is not captured by pharmacy refill data. Future research should incorporate all aspects of the 
$\mathrm{CF}$ treatment regimen to obtain a more accurate depiction of adherence. Because treatment adherence is relatively poor during adolescence (Zindani et al., 2006), it will be important for future research to continue exploring other psychosocial factors that are associated with adherence in an effort to identify targets for interventions aimed at improving treatment adherence. Moreover, transition puts older adolescents at additional risk for poor adherence (Pai \& Ostendorf, 2011), and therefore, it is essential to determine factors (e.g., hope, health locus of control) that may promote adherence as youth begin to move to adult care. 


\section{References}

Abbott, J. \& Gee, L. (1998). Contemporary psychosocial issues in cystic fibrosis:

Treatment adherence and quality of life. Disability and Rehabilitation, 20, 262-271.

Armstrong, B., Mackey, E.R., \& Streisand, R. (2011). Parenting behavior, child

functioning, and health behaviors in preadolescents with type 1 diabetes. Journal of Pediatric Psychology, 36, 1052-1061. doi: 10.1093/jpepsy/jsr039

Bacchini, D. \& Magliulo, F. (2003). Self-image and perceived self-efficacy during adolescence. Journal of Youth and Adolescence, 32, 337-350. doi:

10.1023/A:1024969914672

Baumrind, D. (1966). Effects of authoritative parental control on child behavior. Child Development, 37, 887-907.

Bandura, A. (1994). Self-efficacy. In V. S. Ramachaudran (Ed.), Encyclopedia of human behavior: Vol. 4. (pp. 71-81). Retrieved from http://des.emory.edu/mfp/BanEncy.

Bandura, A. (1977). Self efficacy: Toward a unifying theory of behavioral change. Psychological Review, 84(2), 191-215.

Bandura, A., Barbaranelli, C., Caprara, G. V., \& Pastorelli, C. (1996). Multifaceted impact of self-efficacy beliefs on academic functioning. Child Development, 67, 12061222.

Bartholomew, L. K., Parcel, G. S., Swank, P. R., \& Czyzewski, D. I. (1993). Measuring self-efficacy expectations for the self-management of cystic fibrosis. Chest, 103, 1524-1530. doi:10.1378/chest.103.5.1524 
Baron, R. M., \& Kenny, D. A. (1986). The moderator-mediator variable distinction in social psychological research: Conceptual, strategic, and statistical considerations. Journal of Personality and Social Psychology, 51, 1173-1182.

Berg, C.A., King, P.S., Butler, J.M., Pham, P., Palmer, D., \& Wiebe, D. J. (2011). Parental involvement and adolescents' diabetes management: The mediating role of selfefficacy and externalizing and internalizing behaviors. Journal of Pediatric Psychology, 36, 329-339. doi: 10.1093/jpepsy/jsq088

Bourdeau, T.L., Mullins, L.L., Carpentier, M.Y., Colletti, C.J.M., Wolfe-Christensen, C. (2007). An examination of parenting variables and child self-care behavior across disease groups. Journal of Developmental and Physical Disabilities, 19, 125-134. doi: 10.1007/s10882-007-9037-9

Boyle, M.P., Farukhi, Z., \& Nosky, M.L. (2001). Strategies for improving transition to adult cystic fibrosis care, based on patient and parent views. Pediatric Pulmonology, 32, 428-436.

Burrows, J. A., Bunting, J. P, Masel, P. J., \& Bell, S. C. (2002). Nebulised dornase alpha: Adherence in adults with cystic fibrosis. Journal of Cystic Fibrosis, 1, 255-259.

Butler, J. M., Skinner, M., Gelfand, D., Berg, C. A., \& Wiebe, D. J. (2007). Maternal parenting style and adjustment in adolescents with type I diabetes. Journal of Pediatric Psychology, 32, 1227-1237. doi: 10.1093/jpepsy/jsm065

Caprara, G. V., Pastorelli, C., Regalia, C., Scabini, E., \& Bandura, A. (2005). Impact of adolescents' filial self-efficacy on quality of family functioning and satisfaction. Journal of Research on Adolescence, 15, 71-97. doi: 10.1111/j.15327795.2005.00087.x 
Choo, P. W., Rand, C. S., Inui, T. S., Lee, M. T., Cain, E., Cordeiro-Breault, M., ... Platt, R. (1999). Validation of patient reports, automated pharmacy records, and pill counts with electronic monitoring of adherence to antihypertensive therapy. Medical Care, 37, 846-857.

Colin, A. A. \& Wohl, M. E. B. (1994). Cystic fibrosis. Pediatrics in Review, 15, 192-200. Cystic Fibrosis Foundation. (2011). Patient Registry 2010 Annual Data Report. Bethesda, MD: Cystic Fibrosis Foundation.

Czajkowski, D.R. \& Koocher, G.P. (1986). Predicting medical compliance among adolescents with cystic fibrosis. Health Psychology, 5, 297-305

Czajkowski, D.R. \& Koocher, G.P. (1987). Medical compliance and coping with cystic fibrosis. Journal of Child Psychology and Psychiatry, 28, 311-319.

Davis, C. L., Delamater, A. M., Shaw, K. H., La Greca, A. M., Eidson, M. S., PerezRodriguez, J. E., \& Nemery, R. (2001). Parenting styles, regimen adherence, and glycemic control in 4- to 10-year-old children with diabetes. Journal of Pediatric Psychology, 26, 123-129. doi: 10.1093/jpepsy/26.2.123

DeLambo, K.E., Ievers-Landis, C.E., Drotar, D., \& Quittner, A.L. (2004). Association of observed family relationship quality and problem-solving skills with treatment adherence in older children and adolescents with cystic fibrosis. Journal of Pediatric Psychology, 29, 343-353. doi: 10.1093/jpepsy/jsh038

Desmond, K. J., Schwenk, W.F., Thomas, E., Beaudry, P. H., \& Coates, A. L. (1983). Immediate and long-term effects of chest physiotherapy in patients with cystic fibrosis. The Journal of Pediatrics, 103, 538-42. 
DiGirolamo, A. M., Quittner, A. L., Ackerman, V., \& Stevens, J. (1997). Identification and assessment of ongoing stressors in adolescents with a chronic illness: An application of the behavior analytic model. Journal of Clinical Child Psychology, 26, 53-66.

Drotar, D. \& Ievers, C. (1994). Age differences in parent and child responsibilities for management of cystic fibrosis and insulin-dependent diabetes mellitus. Developmental and Behavioral Pediatrics, 15, 265-272.

Dugueperoux, I., Tamalet, A., Sermet-Gaudelus, I., Le Bourgeois, M., Gerardin, M., Desmazes-Dufeu, N., \& Hubert, D. (2008). Clinical changes of patients with cystic fibrosis during transition from pediatric to adult care. Journal of Adolescent Health, 43, 459-465. doi: 10.1016/j.jadohealth.2008.03.005

Eakin, M. N., Bilderback, A., Boyle, M. P., Mogayzel, P. J., \& Riekert, K. A. (2011). Longitudinal association between medication adherence and lung health in people with cystic fibrosis. Journal of Cystic Fibrosis, 10, 258-264.

doi:10.1016/j.jcf.2011.03.005

Graue, M., Wentzel-Larsen, T., Hanestad, B. R., \& Søvik, O. (2005). Health-related quality of life and metabolic control in adolescents with diabetes: The role of parental care, control, and involvement. International Pediatric Nursing, 20, 373-382. doi:10.1016/j.pedn.2005.08.005

Gudas, L. J., Koocher, G. P., \& Wypig, D. (1991). Perceptions of medical compliance in children and adolescents with cystic fibrosis. Journal of Developmental and Behavioral Pediatrics, 12, 236-242. 
Holman, H. \& Lorig, K. (1992). Perceived self-efficacy in self-management of chronic disease. In R. Schwarzer (Ed.), Self-efficacy: Thoughts control of action (pp. 305323). Washington, DC: Hemisphere.

Ievers, C. E. \& Drotar, D. (1996). Family and parental functioning in cystic fibrosis. Journal of Developmental and Behavioral Pediatrics, 11, 353-358.

Jin, J., Sklar, G. E., Oh, V. M. S., \& Li, S. C. (2008). Factors affecting therapeutic compliance: A review from the patient's perspective. Therapeutics and Clinical Risk Management, 4, 269-286. PMCID: PMC2503662

Johnson, R.J., Adams, C.D., Scotten, M., \& Robinson, K. (2006, August). Regimen experimentation in cystic fibrosis and associated factors. Paper presented as part of a symposium at the annual convention of the American Psychological Association, New Orleans, LA.

Kneeland, P. P. \& Fang, M. C. (2010). Current issues in patient adherence and persistence: Focus on anticoagulants for the treatment and prevention of thromboembolism. Patient preference and adherence, 4, 51-60. PMCID: PMC2846139

Lorig, K. R., Ritter, P. L., Laurent, D. D., \& Plant, K. (2006). Internet-based chronic disease self-management: A randomized trial. Medical Care, 44, 964-971.

Lorig, K., Ritter, P. L., Laurent, D. D., Plant, K., Green, M., Jernigan, V. B., \& Case, S. (2010). Online diabetes self-management program: A randomized study. Diabetes Care, 33, 1275-1281.

Lorig, K., Stewart, A., Ritter, P., González, V., Laurent, D., \& Lynch, J. (1996). Outcome measures for health education and other health care interventions. Thousand Oaks, CA: Sage Publications, pp. 24-25, 41-45. 
McQuaid, E.L., Kopel, S.J., Klein, R.B., \& Fritz, G.K. (2003). Medication adherence in pediatric asthma: Reasoning, responsibility, and behavior. Journal of Pediatric Psychology, 28, 323-333. doi: 10.1093/jpepsy/jsg022

Modi, A.C., Lim, C.S., Yu, N., Geller, D., Wagner, M.H., \& Quittner A.L. (2006). A multimethod assessment of treatment adherence for children with cystic fibrosis. Journal of Cystic Fibrosis, 5, 177-185. doi:10.1016/j.jcf.2006.03.002

Modi, A.C., Marciel, K.K., Slater, S.K., Drotar, D., \& Quittner, A. L. (2008). The influence of parental supervision on medical adherence in adolescents with cystic fibrosis: Developmental shifts from pre to late adolescence. Children's Health Care, 37, 7882. doi: $10.1080 / 02739610701766925$

Modi, A. C. \& Quittner, A. L. (2006). Barriers to treatment adherence for children with cystic fibrosis and asthma: What gets in the way? Journal of Pediatric Psychology, 31, 846-858. doi: 10.1093/jpepsy/jsj096

Mogayzel, P.J., Naureckas, E.T., Robinson, K.A., Mueller, G., Hadjiliadis, D., Hoag, J.B., ...Marshall, B. (2013). Cystic fibrosis pulmonary guidelines: Chronic medications for maintenance of lung health. Pulmonary Clinical Practice Guidelines Committee. American Journal of Respiratory and Critical Care Medicine, 187, 680-689.

Ott, J., Greening, L., Palardy, N., Holderby, A., \& DeBell, W. K. (2000). Self-efficacy as a mediator variable for adolescents' adherence to treatment for insulin-dependent diabetes mellitus. Children's Health Care, 29, 47-63.

Pai, A. L. H. \& Ostendorf, H. M. (2011). Treatment adherence in adolescents and young adults affected by chronic illness during the health care transition from pediatric to 
adult health care: A literature review. Children's Health Care, 40, 16-33. doi: $10.1080 / 02739615.2011 .537934$

Parcel, G. S., Swank, P. R., Mariotto, M. J., Bartholomew, L. K., Czyzewski, D. I., Sockrider, M. M., \& Seilheimer, D. K. (1994). Self-management of cystic fibrosis: A structural model for educational and behavioral variables. Social Science and Medicine, 38, 1307-1315.

Parker, G., Tupling, H., \& Brown, L.B. (1979). A parental bonding instrument. British Journal of Medical Psychology, 52, 1-10.

Quittner, A. L., Barker, D. H., Marciel, K. K., \& Grimley, M. E. (2009). Cystic fibrosis. In M. C. Roberts \& R. G. Steele (Eds.), Handbook of Pediatric Psychology (pp. 271286). New York, NY: The Guilford Press.

Quittner, A. L., Espelage, D. L., Ievers-Landis, C. E., \& Drotar, D. (2000). Measuring adherence to medical treatments in childhood chronic illness: Considering multiple methods and sources of information. Journal of Clinical Psychology in Medical Settings, 7, 41-54.

Quittner, A. L., Tolbert, V. E., Regoli, M. J., Orenstein D., Hollingsworth, J. L., \& Eigen, H. (1996). Development of the Role-play Inventory of Situations and Coping Strategies (RISCS) for parents of children with cystic fibrosis. Journal of Pediatric Psychology, 21, 209-235.

Rapoff, M. A. (1999). Adherence to pediatric medical regimens. New York: Springer.

Ricker, J. H., Delamater, A. M., \& Hsu, J. (1998). Correlates of regimen adherence in cystic fibrosis. Journal of Clinical Psychology in Medical Settings, 5, 159-172. 
Shorer, M., David, R., Schoenberg-Taz, M., Levavi-Lavi, I., Philip, M., \& Meyerovitch, J. (2011). Role of parenting style in achieving metabolic control in adolescents with type 1 diabetes. Diabetes Care, 34, 1735-37. doi: 10.2337/dc10-1602

Strausbaugh, S.D., \& Davis, P.B. (2007). Cystic Fibrosis: A review of epidemiology and pathobiology. Clinics in Chest Medicine, 28, 279-288. doi: 10.1016/j.ccm.2007.02.011

Taylor, N., Absolom, K., Snowden, J., \& Eiser, C. (2012). Need for psychological followup among young adult survivors of childhood cancer. European Journal of Cancer Care, 21, 52-58. doi: 10.1111/j.1365-2354.2011.01281.x

Tuchman, L.K., Schwartz, L.A., Sawicki, G.S., \& Britto, M. (2010). Cystic fibrosis and transition to adult medical care. Pediatrics, 125, 566-573. doi: 10.1542/peds.20092791

Walders, N, Drotar, D, \& Kercsmar, C. (2000). The allocation of family responsibility for asthma management tasks in African-American adolescents. Journal of Asthma, 37, 89-99.

Westwood, A., Henley, L.D., \& Willcox, P. (1999). Transition from paediatric to adult care for persons with cystic fibrosis: Patient and parent perspectives. Journal of Paediatrics and Child Health, 35, 442-445.

Weydert, J. A., Shapiro, D. E., Acra, S. A., Monheim, C. J., Chambers, A. S., \& Ball, T. M. (2006). Evaluation of guided imagery as treatment for recurrent abdominal pain in children: A randomized controlled trial. BMC Pediatrics, 6, 1-10. doi:10.1186/1471-2431-6-29 
White, D., Stiller, K., \& Haensel, N. (2007). Adherence of adult cystic fibrosis patients with airway clearance and exercise regimens. Journal of Cystic Fibrosis, 6, 163170.

White, T., Miller, J., Smith, G.L., \& McMahon, W.M. (2009). Adherence and psychopathology in children and adolescents with cystic fibrosis. European Child and Adolescent Psychiatry, 18, 96-104. doi: 10.1007/s00787-008-0709-5

Williams, B., Mukhopadhyay, S., Dowell, J., \& Coyle, J. (2007). From child to adult: An exploration of shifting family roles and responsibilities in managing physiotherapy for cystic fibrosis. Social Science \& Medicine, 65(10), 2135-2146. doi: 10.1016/j.socscimed.2007.07.020

Zebracki, K. \& Drotar, D. Outcome expectancy and self-efficacy in adolescent asthma selfmanagement. Children's Health Care, 33, 133-149.

Zindani, G.N., Streetman, D.D., Streetman, D.S., \& Nasr, S.Z. (2006). Adherence to treatment in children and adolescent patients with cystic fibrosis. Journal of Adolescent Health, 38(1), 13-17. doi: 10.1016/j.jadohealth.2004.09.013 
Table 1

Sample Demographics

\begin{tabular}{|c|c|c|c|c|}
\hline Variables $(N=59)$ & n (\%) & Mean & SD & Range \\
\hline Patient age & & 15.12 & 2.77 & $11-20$ \\
\hline \multicolumn{5}{|l|}{ Patient gender } \\
\hline Male & $33(55.9 \%)$ & & & \\
\hline Female & $26(44.1 \%)$ & & & \\
\hline \multicolumn{5}{|l|}{ Patient race } \\
\hline White & $56(94.9 \%)$ & & & \\
\hline Black & $1(1.7 \%)$ & & & \\
\hline White/Black & $1(1.7 \%)$ & & & \\
\hline Missing & $1(1.7 \%)$ & & & \\
\hline Hospital days in past 12 months & & 10.41 & 22.91 & $0-118$ \\
\hline $\begin{array}{l}\text { Most recent BMI percentile rank for } \\
11-19 \text { year olds }(n=56)\end{array}$ & & 42.72 & 28.04 & $0.72-99$ \\
\hline $\begin{array}{l}\text { Most recent BMI measurement for } 20 \\
\text { year olds }(n=3)\end{array}$ & & 19.21 & 3.59 & $16.08-23.13$ \\
\hline Most recent $\mathrm{FEV}_{1}$ measurement & & 79.94 & 25.04 & $30-125$ \\
\hline \multicolumn{5}{|l|}{ Primary caregiver relationship } \\
\hline Mother & $43(72.9 \%)$ & & & \\
\hline Father & $13(22.0 \%)$ & & & \\
\hline Grandmother & $2(3.4 \%)$ & & & \\
\hline Grandfather & $1(1.7 \%)$ & & & \\
\hline Primary caregiver age & & 44.56 & 7.91 & $30-65$ \\
\hline \multicolumn{5}{|l|}{ Family structure } \\
\hline Intact & $31(52.5 \%)$ & & & \\
\hline Blended & $5(8.5 \%)$ & & & \\
\hline Single & $23(39 \%)$ & & & \\
\hline \multicolumn{5}{|l|}{ Mother highest education level } \\
\hline Some high school & $6(10.2 \%)$ & & & \\
\hline Graduated from high school & $11(18.6 \%)$ & & & \\
\hline Some college or specialized training & $17(28.8 \%)$ & & & \\
\hline Bachelor's degree & $15(25.4 \%)$ & & & \\
\hline Master's or doctoral degree & $8(13.6 \%)$ & & & \\
\hline Missing & $2(3.4 \%)$ & & & \\
\hline
\end{tabular}


Father highest education level

Some high school

$5(8.5 \%)$

Graduated from high school

$10(16.9 \%)$

Some college or specialized training

$16(27.1 \%)$

Bachelor's degree

$12(20.3 \%)$

Master's or doctoral degree

$4(6.8 \%)$

Missing

$12(20.3 \%)$

Total family income

Less than $\$ 10,000$

$\$ 10,000-14,999$

$\$ 15,000-24,999$

$\$ 25,000-34,999$

$\$ 35,000-49,999$

$\$ 50,000-74,999$

$\$ 75,000-99,999$

$11(18.6 \%)$

$5(8.5 \%)$

$0(0 \%)$

$4(6.8 \%)$

$6(10.2 \%)$

$7(11.9 \%)$

$\$ 100,000$ - 149,999

$14(23.7 \%)$

$6(10.2 \%)$

$\$ 150,000$ or more

$6(10.2 \%)$ 
Table 2

Descriptives of study variables

\begin{tabular}{|c|c|c|c|c|}
\hline $\begin{array}{c}\text { Variables } \\
(\mathrm{N}=59 \text { except were noted })\end{array}$ & Mean & SD & $\begin{array}{l}\text { Possible } \\
\text { Range }\end{array}$ & Site Differences \\
\hline Treatment Adherence ${ }^{1}$ & 20.16 & 18.26 & $0-100$ & $0.93, n s$ \\
\hline Self-efficacy ${ }^{2}$ & 8.18 & 1.62 & $1-10$ & $0.18, n s$ \\
\hline $\begin{array}{l}\text { Level of Responsibility - youth } \\
\text { report } \\
\text { r,4 }\end{array}$ & 3.76 & 0.83 & $1-5$ & $0.81, n s$ \\
\hline $\begin{array}{l}\text { Level of Responsibility - parent } \\
\text { report }\end{array}$ & 3.08 & 0.89 & $1-5$ & $1.83, n s$ \\
\hline Parental style - warmth scale ${ }^{6}$ & 29.07 & 7.00 & $0-36$ & $5.11, p=0.009$ \\
\hline Parental style - protection scale ${ }^{7}$ & 11.64 & 7.37 & $0-39$ & $7.45, p=0.001$ \\
\hline \multicolumn{5}{|c|}{$\begin{array}{l}{ }^{1} \text { Medication Possession Ratio (percentage) } \\
{ }^{2} \text { Higher scores = higher self-efficacy } \\
{ }^{3} \text { Higher scores = higher youth responsibility, lower scores = higher parent responsibility, } \\
\text { score of } 3 \text { = equal parent and youth responsibility } \\
{ }^{4} \mathrm{n}=57 \\
{ }^{5} \mathrm{n}=58 \\
{ }^{6} \text { Higher scores = parental warmth and empathy, lower scores = parental coldness and } \\
\text { neglect } \\
{ }^{7} \text { Higher scores = prevention of autonomy and excessive control, lower scores = } \\
\text { encouragement of autonomy }\end{array}$} \\
\hline
\end{tabular}


Table 3

Moderation with Treatment Adherence and Parental Bonding Instrument (PBI) - warmth scale

\begin{tabular}{|c|c|c|c|c|c|}
\hline $\mathbf{N}=\mathbf{5 7}$ & $\beta$ & $t$ & $F(d f)$ & $p$ & Adj. $R^{2}$ \\
\hline Step 1 & & & $4.06(1,55)$ & 0.05 & 0.05 \\
\hline Maternal level of education & -0.26 & -2.02 & & 0.05 & \\
\hline Step 2 & & & $2.11(3,53)$ & 0.11 & 0.06 \\
\hline \multirow[t]{2}{*}{ Self-efficacy } & -0.05 & -0.36 & & & \\
\hline & & & & 0.72 & \\
\hline PBI - warmth & 0.19 & 1.48 & & 0.15 & \\
\hline Step 3 & & & $1.56(4,52)$ & 0.20 & 0.04 \\
\hline Self-efficacy X PBI - warmth & 0.03 & 0.15 & & 0.88 & \\
\hline
\end{tabular}


Table 4

Moderation with Treatment Adherence and Parental Bonding Instrument (PBI) protection scale

\begin{tabular}{|c|c|c|c|c|c|}
\hline $\mathbf{N}=\mathbf{5 7}$ & $\boldsymbol{\beta}$ & $t$ & $F(d f)$ & $p$ & $\operatorname{Adj} . R^{2}$ \\
\hline Step 1 & & & $4.06(1,55)$ & 0.05 & 0.05 \\
\hline \multirow{2}{*}{ Maternal level of education } & -0.26 & -2.15 & & & \\
\hline & & & & 0.05 & \\
\hline Step 2 & & & $1.74(3,53)$ & 0.17 & 0.04 \\
\hline Self-efficacy & -0.03 & -0.25 & & 0.81 & \\
\hline $\mathrm{PBI}$ - protection & -0.14 & -1.08 & & 0.29 & \\
\hline Step 3 & & & $1.86(4,52)$ & 0.14 & 0.06 \\
\hline Self-efficacy X PBI - protection & -0.21 & -1.45 & & 0.15 & \\
\hline
\end{tabular}

